\title{
Composition of the isotopes on atmospheric aerosol of Tajikistan
}

\author{
Sabur Abdullaev*, Vladimir Maslov, Bahron Nazarov, Hikoyat Kodirova, Rafika Karieva, Abdugani Djuraev, Tavallo \\ Davlatshoev
}

S.U. Umarov Physical -Technical Institute Academy of Sciences of the Republic of Tajikistan

\begin{abstract}
The results of the investigation of the isotopes distributions Tl-208, Pb-212, Ac-228, Pb-214, Bi-214, Th-234, Ra-226, Pb-210, Cs-137, Be-7 and K-40 in the samples of atmospheric aerosol of the southern, central and northern parts of Tajikistan are presented. Significant correlations were found between the concentrations of Cs-137 and Th-234 isotopes (0.95), Cs-137 and Ra-226 (0.95), Ra-226 and Bi-214 (0.84), Ac-228 and Ra-226 (0.75), Pb-210 and Pb-214 (0.69), Ac-228 and Pb-214 (0.64), K-40 and Pb-212 (0.71), Cs-137 and Bi-214 (0.78), Th-234 and Pb-212 (0.67). Correlations between the concentrations of the remaining isotopes are insignificant or negative. The statistical data for dust intrusion shows that the concentration of isotopes $\mathrm{K}-40, \mathrm{Cs}-137$ and $\mathrm{Bi}-214$ exceeds the background pollution level by hundreds of times, and the remaining isotopes - dozens of times.
\end{abstract}

The Republic of Tajikistan is located in the global dust belt, on the way transportation of dust storms from dust sources such as the Sahara, drying Aral Sea Aralkum, Kyzyl-Kum and Karakum, the Iranian deserts Dashti Kabir and Dashti Lut, the Takla-Makan Desert and Gobi. Dust, rising in these deserts, invades the territory of Tajikistan through its southern and western borders in the form of dust haze (DH) or dust storm (DS) [1-3].

The study of aerosol contamination of the atmosphere is relevant for understanding and solving the problems of regional and global transboundary transport of dust. In the cold season, air in southern and central areas of Tajikistan is polluted by emissions from transport, cogeneration plants, housing and communal services, the private sector and the cement plant, and in warmer times the atmosphere of the region is polluted by dust incursions from the south and west part Tajikistan [1-14]. In the north of the country, air pollution is associated with emissions of transport, industrial plants and the transfer of aerosol particles from the surface of open uranium waster tailing of this region [15-20].

The content of isotopes of the uranium and thorium series in the atmospheric aerosol of Tajikistan is investigated by using gamma spectroscopy method described in [14-15]. Samples of aerosols were prepared from dust deposited on the substrate. In southern and central Tajikistan samples were collected annually from April to November during the dust intrusion. In northern Tajikistan, where there are no powerful dust episodes, samples were collected episodically (26 samples). A total of 116 atmospheric aerosol samples were collected during the period from April 2007 to November 2016. The experimental setup and procedure are described in [1114].

The accuracy of the determination of the specific activity of atmospheric aerosol tests was verified on 15 samples on five gamma lines for uranium isotopes and on seven lines of the thorium series [6-9].

The content of isotopes K-40, Cs-137 and Bi-214 is hundreds of times higher than the background pollution level, while the content of other isotopes is ten times higher.

On Tab. 1 it can be seen that the highest concentrations of Cs-137 and K-40 isotopes are determined in the Ayvaj Desert in the south of the country. The content of isotopes Ac-228, Bi-214, Ra-226, Pb-212, Pb-214, Tl-208 and $\mathrm{Pb}-210$ are highest in Dushanbe, and Th-234 in the Zafarabad area in the north of the country. The smallest content of isotopes of Ac-228, Bi-214, Th-234, Ra-226, Cs-137 and K-40 was recorded in the Ayvaj Desert, $\mathrm{Pb}-212$ in Dushanbe, $\mathrm{Pb}-214, \mathrm{Tl}-208$ and $\mathrm{Pb}-210$ in the Zafarabad area.

The results of the investigation of isotopes distribution Tl-208, Pb-212, Ac-228, Pb-214, Bi-214, Th-234, Ra-226, Pb-210, Cs-137, Be-7 and K-40 in dust aerosol samples from the southern, central and northern parts of Tajikistan are presented.

The curves of the average monthly isotope content in the dust intrusion particles in the south of Tajikistan (Ayvaj desert) show (Fig. 1) that the highest Bi-214 isotope content is in October, Tl-208 in September, As-228 and K-40 in April, Pb-214 and Pb-212 in July. The

*Corresponding author: sabur.f.abdullaev@gmail.com 
Table 1. Statistical data on dust aerosol samples (total of 116 samples for 2007-2016). N - number of samples; $<$ C $>$ - is the average isotope content in the sample, $\mathrm{Bq} / \mathrm{kg} ; \mathrm{C}_{\max }$ - maximum isotope content in the sample, $\mathrm{Bq} / \mathrm{kg}$; $\mathrm{St}_{\max }$ - location and date of sampling with maximum concentration; $\mathrm{C}_{\min }$ - minimum isotope content in the sample, $\mathrm{Bq} / \mathrm{kg}$; $\mathrm{St}_{\min }$ - the place and date of sampling with minimal concentration; $\sigma$ - st.deviation; $\mathrm{S}_{\mathrm{n}}$ is the error; IPI - integral index of pollution isotope; I - geochemical index of isotope pollution; $\mathrm{D}_{0}=\mathrm{C}_{\max } / \mathrm{C}_{\min }$ is the ratio of the maximum value to the background value (the minimum isotope content is taken as the background value). A-Ayvadj; D-Dushanbe; Z-Zafarabad.

\begin{tabular}{|l|l|l|l|l|l|l|l|l|l|c|}
\hline $\begin{array}{l}\text { Parameter/ } \\
\text { Isotope }\end{array}$ & $\mathrm{Pb}-214$ & $\mathrm{Bi}-214$ & $\mathrm{Ac}-228$ & $\mathrm{~Pb}-212$ & $\mathrm{Tl}-208$ & $\mathrm{~K}-40$ & $\mathrm{Th}-234$ & $\mathrm{Ra}-226$ & $\mathrm{~Pb}-210$ & $\mathrm{Cs}-137$ \\
\hline$N$ & 97 & 102 & 45 & 97 & 88 & 110 & 7 & 34 & 97 & 24 \\
\hline$\langle C>$ & 37.34 & 35.00 & 58.75 & 42.29 & 30.08 & 752.45 & 47.14 & 106.11 & 1054.15 & 15.16 \\
\hline$C_{\max }$ & 120.90 & 271.70 & 236.68 & 294.66 & 71.95 & 3097.79 & 79.36 & 185.10 & 3480.20 & 63.90 \\
\hline$C_{\min }$ & 2.70 & 2.33 & 14.46 & 5.30 & 1.00 & 3.41 & 26.65 & 48.43 & 67.41 & 0.17 \\
\hline$\sigma$ & 2.17 & 3.98 & 4.90 & 3.30 & 1.46 & 57.48 & 6.21 & 12.15 & 170.94 & 3.67 \\
\hline$S_{n}$ & 0.02 & 0.11 & 0.08 & 0.08 & 0.05 & 0.08 & 0.13 & 0.11 & 0.16 & 0.24 \\
\hline $\mathrm{IPI}$ & 13.83 & 15.02 & 4.06 & 7.98 & 30.08 & 220.66 & 1.77 & 2.19 & 15.64 & 89.18 \\
\hline $\mathrm{I}$ & 3.20 & 3.32 & 1.44 & 2.41 & 4.33 & 7.20 & 0.24 & 0.55 & 3.38 & 5.89 \\
\hline $\mathrm{D}_{0}$ & 44.78 & 116.61 & 16.37 & 55.60 & 71.95 & 908.44 & 2.98 & 3.82 & 51.63 & 375.88 \\
\hline & $\mathrm{D}$ & $\mathrm{D}$ & $\mathrm{D}$ & $\mathrm{D}$ & $\mathrm{D}$ & $\mathrm{A}$ & $\mathrm{Z}$ & $\mathrm{D}$ & $\mathrm{D}$ & $\mathrm{A}$ \\
\hline $\mathrm{St}_{\max }$ & 4.04 .10 & 16.07 .11 & 8.10 .10 & 16.07 .10 & 30.11 .07 & 16.01 .16 & 10.08 .15 & 4.10 .10 & 4.04 .10 & 1.04 .16 \\
\hline $\mathrm{St}_{\min }$ & $\mathrm{Z}$ & $\mathrm{A}$ & $\mathrm{A}$ & $\mathrm{D}$ & $\mathrm{Z}$ & $\mathrm{A}$ & $\mathrm{A}$ & $\mathrm{A}$ & $\mathrm{Z}$ & $\mathrm{A}$ \\
& 12.06 .14 & 10.06 .16 & 19.03 .10 & 8.08 .11 & 12.06 .14 & 10.04 .16 & 8.06 .15 & 19.03 .10 & 12.06 .14 & 8.06 .15 \\
\hline
\end{tabular}

mean monthly course of isotope concentrations has significant variations, the most significant in the autumn. The monthly course of the isotope content (Fig. 2) in the atmospheric aerosol of northern Tajikistan (Yakkabog village, Istaravshan district) shows that from April to October the internal variation of the average monthly content of some isotopes is minimum, which may be related to the meteorological parameters of the atmosphere and the minimum northern winds. Table 2 shows the correlation coefficients of isotopes in dust aerosol particles. A significant correlation was found between the concentrations of the isotopes Cs-137 and Th-234 (0.95), Cs-137 and Ra-226 (0.95), Ra-226 and $\mathrm{Bi}-214$ (0.84), Cs-137 and Bi-214 (0.78), Ac-228 and Ra-226 (0.75), Pb-210 and Pb-214 (0.69), Ac-228 and
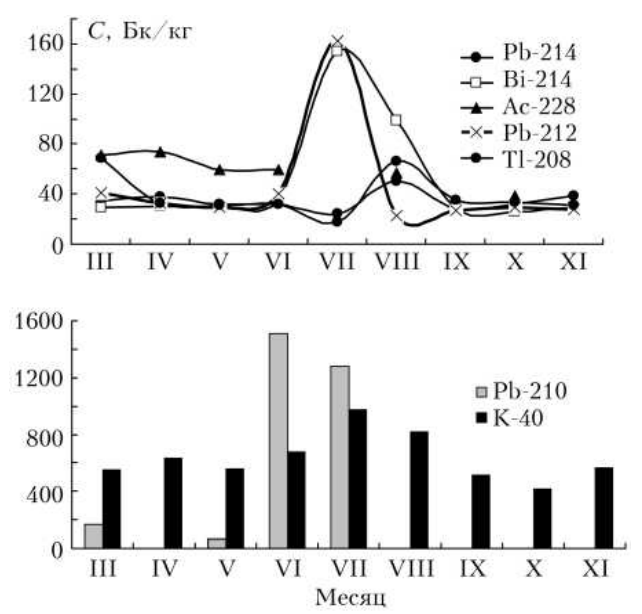

Figure 1. The average monthly content of isotopes in dust aerosol samples from the southern part of Tajikistan (Ayvaj, Shaartuz).
$\mathrm{Pb}-214$ (0.64) and between isotopes of $\mathrm{K}-40$ and $\mathrm{Pb}-212$ (0.71), Th-234 and Ac-228 (0.68), Th-234 and Pb-212 (0.67). The other isotopes do not have a significant correlation or have a negative correlation.
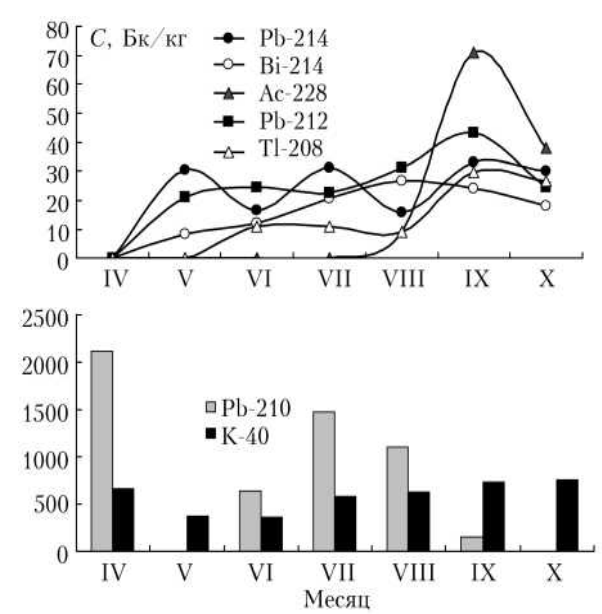

Figure 2. Dynamics of the average monthly isotope content in atmospheric aerosols in the northern part of Tajikistan.

Perhaps this happens as result of different isotopes mechanisms entries in the aerosol samples. Comparison of isotope concentrations in soil and in dust aerosols in the central part of the country (Fig. 3) shows that the concentration of all isotopes in the dust aerosol is greater than in the soil of the distribution zones of the DS, which indicates dust intrusions (DH) from neighboring countries. The concentration of the $\mathrm{Pb}-210$ isotope in the dust aerosol is much larger than in the soil of the southern part of the country. For other isotopes, the ratio is inverse. 
Table 2. Correlation coefficients between contained isotopes in dust aerosol samples (116 samples, 2007-2016).

\begin{tabular}{|l|l|l|l|l|l|l|l|l|l|}
\hline Isotope & Bi-214 & Pb-212 & Tl-208 & K-40 & Th-234 & Ra-226 & Pb-210 & Cs-137 & Ac-228 \\
\hline $\mathrm{Pb}-214$ & 0.35 & 0.51 & 0.10 & 0.41 & -0.17 & 0.74 & 0.69 & 0.63 & 0.64 \\
\hline $\mathrm{Bi}-214$ & & 0.01 & 0.19 & 0.18 & 0.34 & 0.84 & 0.04 & 0.78 & 0.44 \\
\hline $\mathrm{Pb}-212$ & & & 0.19 & 0.71 & 0.67 & 0.45 & 0.63 & 0.27 & 0.41 \\
\hline $\mathrm{Tl}-208$ & & & & 0.24 & 0.40 & 0.24 & 0.25 & 0.87 & 0.07 \\
\hline $\mathrm{K}-40$ & & & & & 0.39 & 0.44 & -0.41 & 0.40 & 0.41 \\
\hline Th-234 & & & & & & 0.55 & 0.48 & 0.95 & 0.68 \\
\hline $\mathrm{Ra}-226$ & & & & & & & -0.63 & 0.95 & 0.75 \\
\hline $\mathrm{Pb}-210$ & & & & & & & & 0.54 & 0.63 \\
\hline $\mathrm{Cs}-137$ & & & & & & & & & 0.27 \\
\hline
\end{tabular}

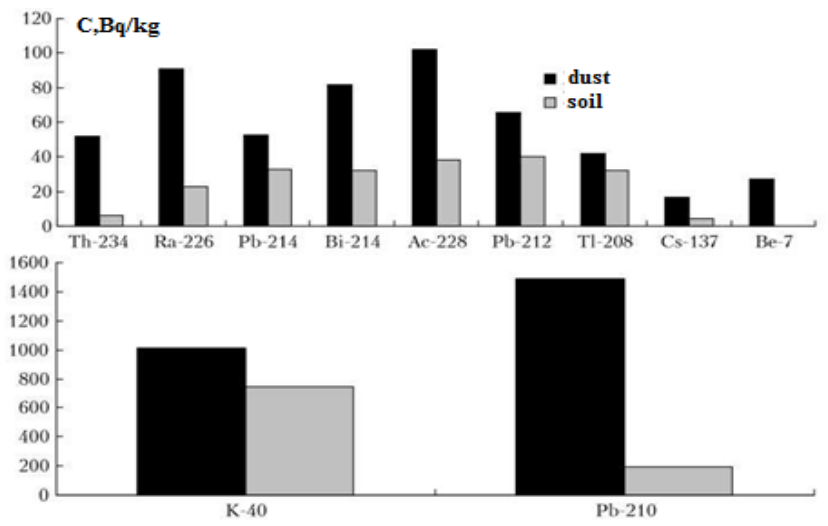

Figure 3. Concentration isotopes in samples of dust aerosol and soil in the central part of Tajikistan.

The isotope Be-7 was detected in only three samples of aerosols: from the deserts of Ayvaj (19.03.2010, $25 \mathrm{~Bq} / \mathrm{kg}$ ) and in Dushanbe (16.09.2010, $28 \mathrm{~Bq} / \mathrm{kg}$ and 8.10.2010, $26 \mathrm{~Bq} / \mathrm{kg}$ ).

Comparison of the data proves that in the northern part of the country the content of isotopes, with the exception of the isotope $\mathrm{Pb}-210$, is greater in the soil than in the dust sediments. This indicates high soil contamination in this region. This is obviously related to the accumulation of uranium deposits (yielding to high background levels of radioactivity) and the presence of open tailing dumps and industrial facilities over many years.

Inter annual variations in the concentrations of isotopes in dust aerosol particles (Fig. 3) indicate that in 2009 there were maximum concentrations of isotopes Th-234, Pb-212, Pb-214, Bi-214, in 2010 - Ac-228, in 2011 - Ra-226, Cs-137, in 2014 - Pb-210 and in 2016 $\mathrm{K}-40$. This indicates various sources of dust aerosol generation and, apparently, is associated with its longrange transport. Thus, it has been established that the content of uranium and thorium isotopes in dust aerosol samples collected after a dust invasion exceeds by tens of times their content in the soils of the distribution zone of $\mathrm{DH}$, which indicates the enrichment of DS particles in neighboring countries (Afghanistan Pakistan, Iran, China, India, Syria, and Iraq). The high content of radioactive isotopes of the uranium and thorium series, found in the soils of northern Tajikistan, indicates the influence of open waste tailings and the accumulated background effects from industrial enterprises in the region. In general, the greatest isotope content of $\mathrm{Pb}-214$, $\mathrm{Bi}-214, \mathrm{Ac}-228, \mathrm{~Pb}-212, \mathrm{Tl}-208, \mathrm{Ra}-226$ and $\mathrm{Pb}-210$ is recorded in the center (Dushanbe), isotope Th-234 - in the northern regions of the country, isotopes K-40 and Cs-137 - in the southern regions. It can be assumed that a significant part of radionuclides in the center of Tajikistan is transferred by dust intrusions from the south and west part of the country.

Acknowledgment: The studies were carried out with the financial support of the International Science and Technology Center (ISTC) Projects T-1688 and T-2076. The studies were carried out also with the financial support of Academy of Sciences of the Republic of Tajikistan.

\section{References}

[1] G.S. Golitsyn (ed.), Soviet-American experiment on the study of arid aerosol [in Russian] (1992)

[2] B.D. Belan, V.E. Zuev, M.V. Panchenko, Atmos. Ocean. Opt. 8, 131-156 [in Russian] (1995)

[3] M.V. Panchenko, S.A. Terpugova, B.A. Bodhaine, A.A. Isakov, M.A. Sviridenkov I.N. Sokolik, E.V. Romashova, B.I. Nazarov, A.Kh. Shukurov, E.I. Chistyakova, T.C. Johnson Atmos. Environ. 27(16), 2503-2508 (1993)

[4] D.A. Gillette, J.P. Dobrowolski, Atmos. Environ. 27(16), 2519-2525(1993)

[5] D.A. Gillette, B.A. Bodhaine, D. Mackinnon, Atmos. Environ. 27(16), 2545-2552 (1993)

[6] G.S. Golitsyn, D.A. Gillette, Atmos. Environ. 27(16), 2467-2470 (1993)

[7] I.N. Sokolik, G.S. Golitsyn, Atmos. Environ. 27(16), 2509-2517 (1993) 
[8] Yu.A. Pkhalagov, V. Uzhegov, N. Shelkanov, Atmos. Ocean. Opt. 9(7), 945-951 [in Russian] (1996)

[9] V.E. Pavlov, A.S. Shestukhin, Atmos. Ocean. Opt. 8(3), 252-255 [in Russian] (2005)

[10] J. Hofer, D. Althausen, S.F. Abdullaev, A.N. Makhmudov, B.I. Nazarov, G. Schettler, R. Engelmann, H. Baars, K.W. Fomba, K. Müller, B. Heinold, K. Kandler, A. Ansmann, Atmos. Chem. Phys. 17, 14559-14577 (2017)

[11] S.F. Abdullaev, B.I. Nazarov, V.A. Maslov, A.A. Djuraev, Atmos. Ocean. Opt. 26(3), 187-193 (2013)

[12] S.F. Abdullaev, B.I. Nazarov, V.A. Maslov, A.A. Djuraev, Atmos. Ocean. Opt. 26(5), 396-403 [in Russian] (2013)

[13] S.F. Abdullaev, V.A. Maslov, B.I. Nazarov, U. Madvaliev, A.A. Djuraev, T. Davlatshoev, Atmos. Ocean. Opt. 27(3), 207-214 [in Russian] (2014)

[14] S.F. Abdullaev, V.A. Maslov, B.I. Nazarov, U. Madvaliev, T. Davlatshoev, Atmos. Ocean. Opt. 28(2), 143-152 [in Russian] (2015)

[15] S.F. Abdullaev, V.A. Maslov, B.I. Nazarov, U. Madvaliev, T. Davlatshoev, Atmos. Ocean. Opt. 28(3), 246-255 [in Russian] (2015)

[16] S.F. Abdullaev, V.A. Maslov, B.I. Nazarov, U. Madvaliev, T. Davlatshoev, Atmos. Ocean. Opt. 28(4), 347-358 [in Russian] (2015)

[17] Kh.M. Nazarov, J.A. Salomov, N. Khakimov F.J. Salomov, N.N. Rakhmatov, Izv. AS RT 2(159), 7882 [in Russian] (2015)

[18]B.D. Boboev, Kh.M. Nazarov, J.A. Salomov, E.A. Ermatov, V.M. Miryakhyaev, Izv. AS RT 2(159), 8386 [in Russian] (2015)

[19] Kh.M. Bazarov, J.A. Salomov, B. Khakimov, B.B. Rakhmatov, E.A. Ermatov, Izv. AS RT 2(159), 87-92 [in Russian] (2015)

[20]Kn.M. Nazarov, I.U. Mirsaidov. International Symposium on Uranium Raw Material for the Nuclear Fuel Cycle: Exploration, Mining, Production, Supply and Demand, Economics and Environmental Issues, 23-27 June, 2014, Vienna, Austria. [in Russian] (2014) 